\title{
Treatment with CD20-specific antibody prevents and reverses autoimmune diabetes in mice
}

\author{
Chang-yun Hu, ${ }^{1}$ Daniel Rodriguez-Pinto, ${ }^{1}$ Wei Du, ${ }^{1}$ Anupama Ahuja, ${ }^{2}$ \\ Octavian Henegariu, ${ }^{3}$ F. Susan Wong, ${ }^{4}$ Mark J. Shlomchik, ${ }^{2}$ and Li Wen'
}

${ }^{1}$ Section of Endocrinology, Department of Internal Medicine, ${ }^{2}$ Department of Laboratory Medicine and Immunobiology, and ${ }^{3}$ Department of Immunobiology, Yale School of Medicine, New Haven, Connecticut, USA. ${ }^{4}$ Department of Cellular and Molecular Medicine, University of Bristol, Bristol, United Kingdom.

\begin{abstract}
The precise roles of $B$ cells in promoting the pathogenesis of type 1 diabetes remain undefined. Here, we demonstrate that $B$ cell depletion in mice can prevent or delay diabetes, reverse diabetes after frank hyperglycemia, and lead to the development of cells that suppress disease. To determine the efficacy and potential mechanism of therapeutic B cell depletion, we generated a transgenic NOD mouse expressing human CD20 (hCD20) on B cells. A single cycle of treatment with an antibody specific for hCD20 temporarily depleted B cells and significantly delayed and/or reduced the onset of diabetes. Furthermore, disease established to the point of clinical hyperglycemia could be reversed in over one-third of diabetic mice. Why B cell depletion is therapeutic for a variety of autoimmune diseases is unclear, although effects on antibodies, cytokines, and antigen presentation to $T$ cells are thought to be important. In B cell-depleted NOD mice, we identified what we believe is a novel mechanism by which $B$ cell depletion may lead to long-term remission through expansion of Tregs and regulatory B cells. Our results demonstrate clinical efficacy even in established disease and identify mechanisms for therapeutic action that will guide design and evaluation of parallel studies in patients.
\end{abstract}

\section{Introduction}

Type 1 diabetes (T1D) is an autoimmune disease in which T cells mediate damage to pancreatic islet $\beta$ cells. Despite the primary role of T cells, data from the NOD mouse model indicate that B cells are required for disease induction (1-3) and are likely to have a number of roles in pathogenesis (reviewed in ref. 4). Although direct mechanistic evidence for $\mathrm{B}$ cells promoting T1D in humans is lacking, the production of autoantibodies to islet antigens, including insulin (5), glutamic acid decarboxylase (6), and the tyrosine phosphatase IA-2 $(7,8)$, is well documented and was one of the earliest indicators of disease onset $(9-11)$. These autoantibodies are also very useful predictors of the future development of diabetes in prediabetic individuals (12). In the NOD model, mice genetically deficient in $B$ cells from birth develop a very low incidence of diabetes $(1,13)$. The antigen specificity of $\mathrm{B}$ cells is important, as a major function of B cells is to present antigens to T cells (14-18), leading to diversification of the immune response (19). Although the production of autoantibodies is not absolutely necessary for diabetes to occur, it is an indicator of development of diabetes in NOD mice (5). Interestingly, transplacentally transmitted autoantibodies play an as-yetundefined role in the development of insulitis (20). This suggests that autoantibodies may facilitate or enhance T1D development, although they do not induce the disease.

Thus, in both humans and the NOD mouse model, B cells are involved in disease pathogenesis, probably at different stages. This suggests that depletion of B cells may be useful in altering the development of diabetes. B cell depletion therapy for other autoimmune diseases has recently been studied $(21,22)$. Rituximab,

Nonstandard abbreviations used: BMDC, BM-derived DC; hCD20, human CD20; ipGTT, i.p. glucose tolerance test; T1D, type 1 diabetes.

Conflict of interest: The authors have declared that no conflict of interest exists. Citation for this article: J. Clin. Invest. 117:3857-3867 (2007). doi:10.1172/JCI32405. a humanized anti-human CD20 (anti-hCD20) mAb, can successfully deplete human B cells from peripheral blood lymphocytes for periods ranging from 3 months to more than 1 year (21) through mechanisms involving Fc- and complement-mediated cytotoxicity as well as possible proapoptotic and other signals (23). It has been approved for clinical use and has been given to many B cell lymphoma patients in the last decade (24). Rituximab has also shown efficacy in treating autoimmune diseases such as RA, SLE, and immune-mediated thrombocytopenia (25-27). Efficacy in RA is of particular interest given the prominent role $T$ cells are thought to have in the pathogenesis. However, it is not clear how B cell depletion ameliorates autoimmune diseases. Furthermore, no preclinical study has shown that this approach will be effective in treating T1D. Thus, there are many preclinical questions that should be addressed in consideration of this therapy in diabetes. It is crucial to determine the timing and duration of $\mathrm{B}$ cell depletion therapy in early T1D. Similarly, if B cell depletion is effective, we will want to know the mechanisms, which will shed light on diabetes pathogenesis as well as help in designing optimal therapy. This was not possible to study in a mouse model, due to lack of antibody, until recently $(28,29)$. To address these issues, we developed a NOD mouse model expressing transgenic hCD20 (hCD20/NOD), which allows B cell depletion with anti-hCD20, and have tested to determine whether timed B cell depletion will (a) prevent type I diabetes; (b) block disease progression; and (c) ameliorate disease.

\section{Results}

Characterization of hCD20/NOD mice. To test the efficacy of antihCD20 in prevention and treatment of autoimmune diabetes, we generated a bacteria artificial chromosome-transgenic NOD mouse that expresses hCD20 on B cells (Figure 1A). The expression of hCD20 did not have any obvious effect on general mouse development. No gross abnormality was found in development of the 
A

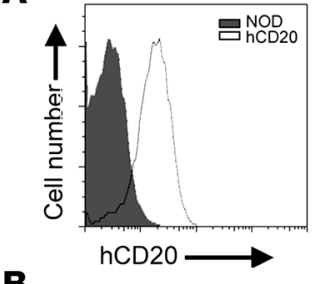

B

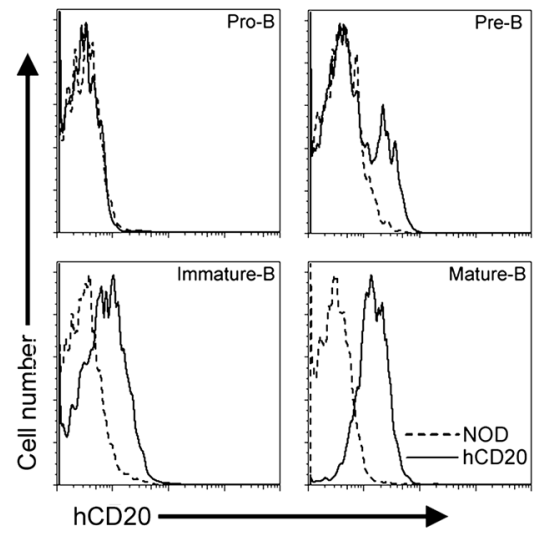

C

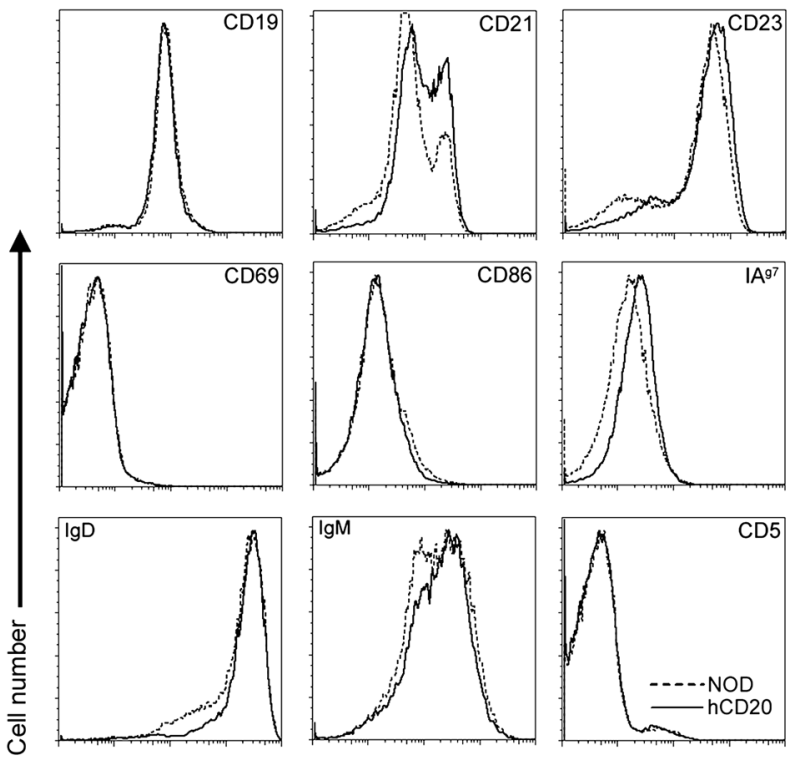

\section{Figure 1}

Phenotypic expression of transgenic hCD20 on B cells. (A) Splenocytes from hCD20 mice were gated on B220+ B cells and stained with antihCD20 mAbs (2H7). All mature B cells expressed the transgenic hCD20. (B) Expression of hCD20 in BM cells of transgene-positive and control NOD mice. (C) Phenotypic characterization of hCD20 transgene-positive and control NOD mouse spleen cells. The splenocytes were gated on $\mathrm{B} 220^{+}$cells prior to analyzing for the different $\mathrm{B}$ cell markers.

immune system in the transgenic mice (data not shown). Similar to the expression of endogenous mouse CD20 (28-30), the expression of transgenic hCD20 occurred from the pre-B cell stage to mature $\mathrm{B}$ cells (Figure 1B). The expression of hCD20 was restricted to B cells only $\left(\mathrm{B} 220^{+} \mathrm{CD} 19^{+}\right)$(Supplemental Figure 1A; supplemental material available online with this article; doi:10.1172/ JCI32405DS1). B cell development and the expression of other B cell markers including MHC class II (I-Ag ${ }^{7}$ ) and the costimulatory molecule (CD86) in hCD20/NOD mice were similar to nontransgenic NOD mice (Figure 1C).

Expression of hCD20 did not obviously alter the production of natural immunoglobulins (Supplemental Figure 1B), anti-insulin autoantibodies (Supplemental Figure 1C), or immune responses to foreign antigens, such as OVA, after immunization (data not shown). Expression of hCD20 also did not alter the upregulation of costimulatory molecules by B cells stimulated with anti-Ig or anti-CD40 (Supplemental Figure 1D). Most importantly, the hCD20 transgene did not affect the natural history of diabetes development, as the incidence of diabetes was very similar in both transgenic hCD20/NOD and nontransgenic groups (Figure 2). However, expression of hCD20 allowed us to use $2 \mathrm{H} 7$, a mouse anti-hCD20 mAb that targets the same epitope as rituximab, to specifically deplete $B$ cells. We were able, therefore, to investigate the role of B cells in diabetes development at different stages and to test the efficacy of anti-hCD20 treatment in the disease.

Kinetics of B cell depletion in bCD20/NOD mice and the function of repopulated $B$ cells. To optimize the depletion protocol, we performed pilot experiments using different doses of $2 \mathrm{H} 7(2 \mathrm{mg}, 1 \mathrm{mg}, 0.5 \mathrm{mg}$, and $0.25 \mathrm{mg}$ per mouse) and different injection routes (i.p. or i.v.). Our results showed that a 9-day cycle of 4 i.v. injections with a 3-day interval provided the most effective B cell depletion in hCD20/ NOD mice (data not shown). In peripheral blood, depletion was observed as early as 1 hour after the first injection (Supplemental Figure 2), and B cells were almost completely depleted within 1 week after the last anti-hCD20 antibody injection (Figure 3). B cells started to repopulate 3 weeks after the last injection and reached normal levels by 12 weeks after the last injection (Figure 3 ).

The efficiency of B cell depletion varied in different organs (Supplemental Figure 3). Four days after the last injection of anti-CD20 $\mathrm{mAbs}$, more than $90 \%$ of $\mathrm{B}$ cells were depleted in peripheral blood and mesenteric lymph nodes. The depletion was also effective in axillary lymph nodes and BM, but less complete in spleen, ranging from $50 \%$ to $70 \%$ depletion compared with controls (Supplemental Figure 3). Consistent with recent studies by other investigators using antimouse CD20 $(28,29)$, B cells in the peritoneal cavity of hCD20/NOD mice were more resistant to depletion (31) (data not shown).

To examine the function of the repopulated B cells, we immunized mice 2 months after anti-hCD20 treatment with OVA, using alum as adjuvant, when approximately $60 \%$ to $70 \%$ of B cells had been repopulated. IgG-treated mice were used as controls. OVAspecific antibody responses 2 weeks after immunization were comparable between mice that had been treated with anti-hCD20 and mice without treatment (Supplemental Figure 4).

Effect of anti-CD20 treatment on spontaneous diabetes development in hCD20/NOD mice. To test the role of B cells in the preclinical stages of diabetes development, we treated 4- and 9-week-old female hCD20/NOD mice with $2 \mathrm{H} 7$ or control IgG using 1 treatment cycle (9-day period with 4 injections at 3-day intervals). These ages were chosen because, in our NOD colony, 4-week-old mice had little or no pancreatic infiltration while almost all 9-week-old mice 
A

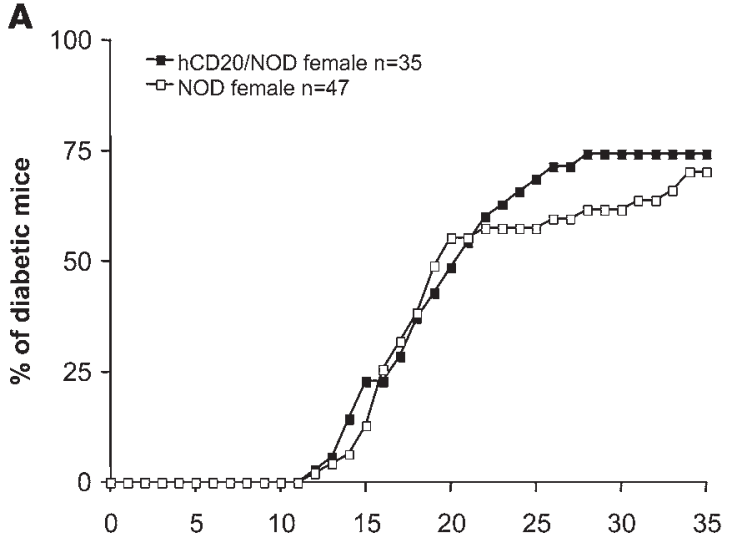

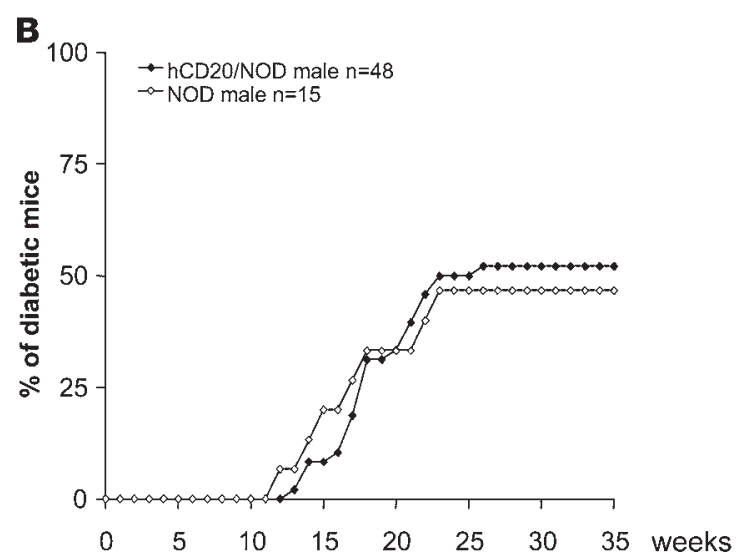

Figure 2

Expression of hCD20 does not affect spontaneous diabetes in NOD mice. The incidence of diabetes in transgenic hCD20 mice was compared with nontransgenic mice (A, female mice; and B, male mice). No differences were seen in diabetes incidence $(P=0.47$ when female incidence curves compared by log-rank test and $P=0.84$ when male incidence curves compared).

displayed insulitis in females. Mice received $0.5 \mathrm{mg}$ antibody in the first injection and $0.25 \mathrm{mg}$ for the subsequent 3 injections. Diabetes development was monitored to 35 weeks of age. Figure 4, A and B, shows that temporary depletion of B cells by a single cycle of antihCD20 treatment significantly delayed the progression of diabetes in both 4 - and 9 -week-old female mice $(P=0.0002$ and $P=0.016$, respectively) and also reduced the overall incidence of diabetes in female mice treated at 9 weeks of age. Delay in diabetes in the 4-week-old mice suggests that B cells are important in initiation of islet $\beta$ cell destruction. The results from the prediabetic 9 -week-old mice indicate that $\mathrm{B}$ cells play an important role in diabetes progression. Similar results were also obtained in male hCD20/NOD mice, but these were not statistically significant $(P=0.06$ and $P=0.07$, respectively) as a result of the general phenomenon of later diabetes onset in male NOD mice (data not shown). As expected, antihCD20 treatment reduced the production of anti-insulin autoantibody either 2 or 7 months after treatment compared with the control group (Supplemental Figure 5).

Effect on established clinical diabetes. To determine whether B cells play a continuing role in established clinical diabetes and are thus a good treatment target, we treated new-onset diabetic (blood glucose ranging from 250 to $500 \mathrm{mg} / \mathrm{dl}$ ) hCD20/NOD mice within 6 days of diagnosis with anti-hCD20 $(n=14)$ or control IgG $(n=10)$ using the same treatment protocol. Diabetic hCD20/NOD mice were given a subtherapeutic dose of insulin soon after diagnosis in order to maintain the animals in a hyperglycemic state but in relatively good general health. Their blood glucose was monitored every 24 ( \pm 1 to 2 ) hours, and the subtherapeutic dose of insulin was withdrawn if blood glucose was less than $250 \mathrm{mg} / \mathrm{dl}$. Of 14 of the anti-CD20-treated mice, 5 (36\%) demonstrated declining blood glucose and required no further insulin treatment, remaining euglycemic for over 2 months after $2 \mathrm{H} 7$ treatment (Figure $5 \mathrm{~A}$ ). Four of these 5 mice remained euglycemic for over 130 days. In contrast, none of the IgG-treated mice had a sustained decline of blood glucose, and all required subtherapeutic doses of insulin treatment (Figure 5B, comparison of 5A with 5B; $P=0.03$ ). To investigate the function of islet $\beta$ cells in the euglycemic mice, we challenged them with a glucose tolerance test via i.p. injection (ipGTT) (at $1.5 \mathrm{mg} / \mathrm{g}$ body weight) after fasting overnight. We used newly diagnosed diabetic female NOD mice $(n=5)$ as controls for dysfunctional islet $\beta$ cells and young nondiabetic female NOD mice $(n=5)$ as controls for functional islet $\beta$ cells. As shown in Figure 5C, the $2 \mathrm{H} 7$-treated euglycemic mice were able to regulate their blood glucose to below $250 \mathrm{mg} / \mathrm{dl}$ (the diagnostic level) 30 minutes after glucose challenge albeit less effectively than young NOD mice. In contrast, blood glucose in newly diabetic NOD mice remained at high levels 2 hours after glucose challenge, as expected (Figure 5C).

Effect of anti-CD20 treatment on cellular infiltrate of pancreatic islets. Randomly selected mice were sacrificed 1 or 2 months after the end of the treatment period in both the groups initially treated at 4 weeks and 9 weeks. Representative histology for each of these groups is shown in Figure 6A, and insulitis scores in these mice are shown in Figure 6B. There was significantly less infiltration in mice treated with $2 \mathrm{H} 7$ compared with the IgG-treated groups at both the 1- and 2-month time points after treatment. At the termination of the experiments, when the mice were over 8 months of age, the histology in the small number of nondiabetic IgG-treated mice was similar to that seen in the nondiabetic $2 \mathrm{H} 7$ -

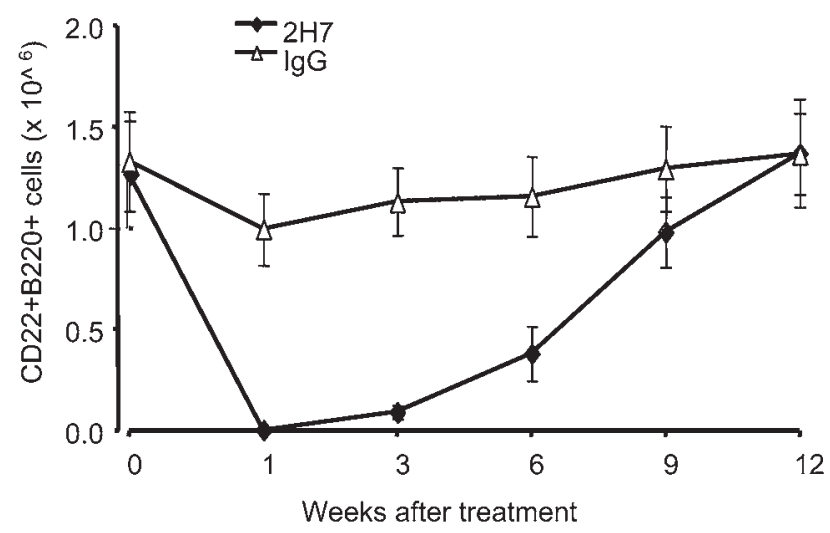

Figure 3

Depletion of B cells following initiation of a course of $42 \mathrm{H} 7$ anti-hCD20 or IgG control injections. Peripheral blood cells, after removing erythrocytes, were costained with anti-CD22 and anti-B220 and analyzed by flow cytometry. B cell $\left(\mathrm{CD} 22^{+} \mathrm{B} 220^{+}\right)$numbers are shown at various time points after the last injection with $2 \mathrm{H} 7$ (circles) or control IgG (triangles). Mean values of at least 10 observations \pm SE are presented. 
A

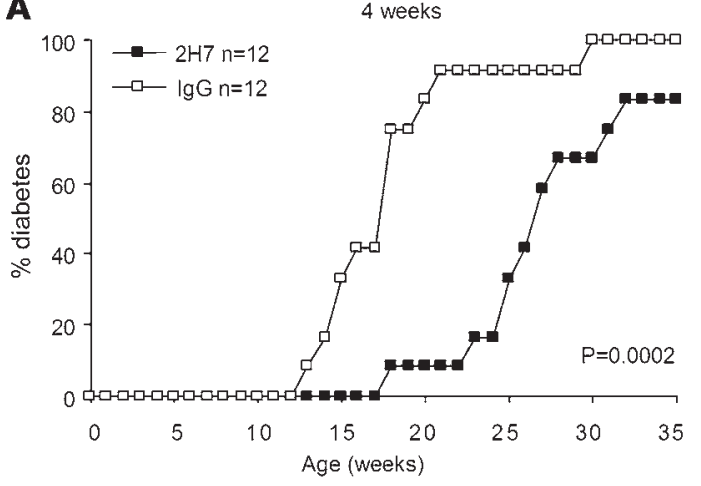

B

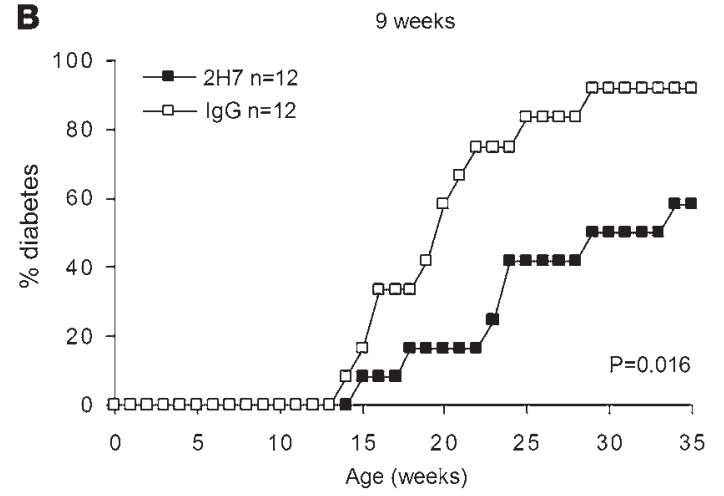

\section{Figure 4}

Diabetes incidence following $2 \mathrm{H} 7$ or control IgG treatment at different ages. (A) Four-week-old and (B) 9-week-old hCD20 female mice were treated 4 times within 10 days with $2 \mathrm{H} 7$ (closed squares; $n=12$ ) or control IgG (open squares; $n=12$ ) antibodies and monitored for diabetes.

treated mice. As expected, no obvious differences were detected in the classic NOD histology among frankly diabetic mice in any group (data not shown).

Despite euglycemia, insulitis in the cured mice, which were euglycemic for over 4 months after anti-hCD20 treatment, was not strikingly different compared with mice that remained hyperglycemic after anti-hCD20 or control IgG treatment (Supplemental Figure 6). It is possible that the reversal was not permanent and the mice might have been on the edge of "relapsing" to clinical diabetes, as insulitis is likely to be a dynamic process. Alternatively, as insulitis is not necessarily synonymous in other settings with $\beta$ cell destruction, it is possible that the quality of the insulitis had been altered or that the process was being actively regulated (see below).

Effect of anti-CD20 treatment on induced diabetes development in NOD/SCID mice. The results from both prevention and treatment experiments shown above suggested that $2 \mathrm{H} 7$ treatment induced a long-lasting suppression of islet autoimmunity. It seems likely that temporary removal of B cells suppressed the development of diabetogenic $T$ cells and reduced islet autoantibody production by newly generated $B$ cells. It is also possible that short-term depletion of B cells induced immune tolerance, given the fact that diabetes protection and reversal were so durable. To test for development of dominant immune tolerance, we performed adoptive transfer experiments $(2,32)$. NOD/SCID mice were given $10^{7}$ NOD splenocytes from diabetic mice i.v., alone or together with $10^{7}$ splenocytes from 2H7-treated or IgG-treated nondiabetic hCD20/NOD mice, obtained at 35 weeks of age (after they had been fully repopulated with $\mathrm{B}$ cells for a few months). We also injected a fourth group of NOD/SCID mice with $10^{7}$ splenocytes from $2 \mathrm{H} 7$-treated nondiabetic mice alone. Diabetes development was monitored for 12 weeks after adoptive transfer. As expected $(2,32)$, splenocytes from diabetic mice induced diabetes in NOD/SCID recipients around 3 weeks after transfer (Figure 7A). NOD/SCID mice that received splenocytes from diabetic mice together with splenocytes from IgG-treated nondiabetic mice also developed diabetes with similar kinetics (Figure 7A). Strikingly, in mice that received splenocytes from diabetic donors together with splenocytes from anti-hCD20treated nondiabetic mice, diabetes was substantially delayed $(P=0.007)$. This indicated that splenocytes from anti-CD20treated mice that remained nondiabetic had a regulatory effect on diabetogenic spleen cells. Thus, B cell depletion in NOD mice unexpectedly induced cells that can dominantly suppress diabeto- genic effector T cells. The results from NOD/SCID recipients that received splenocytes from $2 \mathrm{H} 7$-treated nondiabetic mice alone also supported this notion, as none of these recipients developed diabetes (Figure 7A).

To further investigate which cell population(s) mediated the dominant suppression of diabetes induction in NOD/SCID mice, we performed the following additional sets of adoptive transfer experiments: (a) NOD/SCID mice were given $10^{7}$ splenocytes from NOD mice alone or (b) together with purified splenic $\mathrm{CD}^{+}$ T cells $\left(3 \times 10^{6} /\right.$ mouse, $\left.n=3\right)$ or (c) B cells $\left(3 \times 10^{6} /\right.$ mouse, $\left.n=3\right)$ from $2 \mathrm{H} 7$-treated nondiabetic mice. As controls, splenocytes from NOD mice were also administered with purified splenic $\mathrm{CD}^{+} \mathrm{T}$ cells $\left(3 \times 10^{6} /\right.$ mouse, $\left.n=3\right)$ or B cells $\left(3 \times 10^{6} /\right.$ mouse, $\left.n=3\right)$ from diabetic mice. As further controls, purified splenic B cells or CD4 $\mathrm{T}$ cells $\left(3 \times 10^{6} /\right.$ mouse $)$ from $2 \mathrm{H} 7$-treated nondiabetic mice were also transferred without splenocytes from diabetic mice $(n=3$ each group). Since most IgG-treated mice developed diabetes, it was not possible to use nondiabetic purified B cell or CD4 T cell control groups. As expected, NOD splenocytes from diabetic mice alone induced diabetes in $100 \%$ of the recipients by 4 weeks after transfer (Figure 7B). In sharp contrast, none of the NOD/SCID recipients developed diabetes after infusion of purified $\mathrm{B}$ cells or $\mathrm{CD}^{+} \mathrm{T}$ cells from $2 \mathrm{H} 7$-treated nondiabetic mice (Figure $7 \mathrm{~B}$ ). Both $\mathrm{CD}^{+}{ }^{+} \mathrm{T}$ cells and $\mathrm{B}$ cells from $2 \mathrm{H} 7$-treated nondiabetic mice significantly delayed diabetes development in NOD/SCID mice when cotransferred with diabetic NOD splenocytes (Figure 7B; $P=0.029$ for both). It is intriguing that $\mathrm{B}$ cells expressed a stronger immunoregulatory effect compared with $\mathrm{CD}^{+} \mathrm{T}$ cells (Figure $7 \mathrm{~B}$ ). As expected, CD4 T cells or B cells from diabetic mice did not confer protection (data not shown). Thus, these experiments confirm our initial series of experiments and further establish that either $\mathrm{B}$ or $\mathrm{T}$ cells from $2 \mathrm{H} 7$-treated nondiabetic mice are sufficient to transfer the regulatory effect.

Anti-hCD20 treatmentexpanded $C D 4^{+} \mathrm{CD} 25^{+} \mathrm{Foxp}^{+}$and CTLA4 $4^{+}$Tcells. To investigate the immunosuppressive mechanism mediated by $\mathrm{CD}^{+} \mathrm{T}$ cells, we assessed whether the depletion of B cells affected subsets of $\mathrm{T}$ cells previously shown to have regulatory activity (Tregs). We used FoxP3 as a marker for Tregs (33-35) along with CD4 and CD25 and analyzed splenocytes of nondiabetic hCD20/ NOD mice 6 months after $2 \mathrm{H} 7$ or control IgG treatment. There was an increase of $\mathrm{CD} 4^{+} \mathrm{CD} 25^{+} \mathrm{FoxP} 3^{+}$Tregs in anti-CD20-treated mice compared with $\mathrm{CD} 4^{+} \mathrm{CD} 25^{+} \mathrm{Foxp}^{+}$cells observed in control 
A
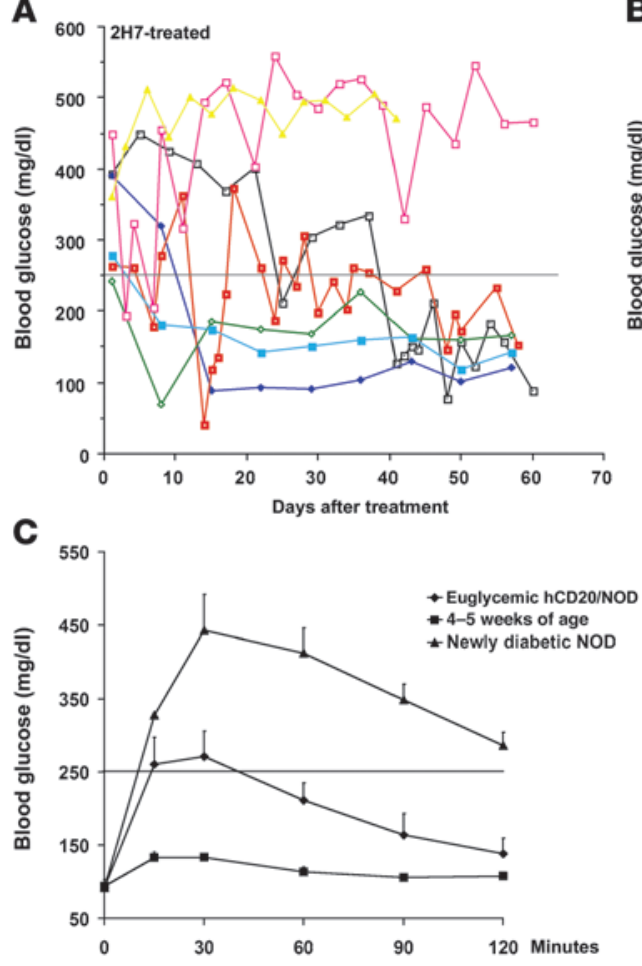

Figure 5

Diabetes reversal following $2 \mathrm{H} 7$ treatment. Diabetic hCD20 mice were treated within 6 days of diagnosis with (A) $2 \mathrm{H} 7$ or (B) IgG as described in the legend for Figure 3, and their blood glucose was monitored daily. A subtherapeutic dose of insulin was administered, and this was discontinued when the blood glucose level was reduced to less than $250 \mathrm{mg} / \mathrm{dl}$. Seven of the 14 mice treated with $2 \mathrm{H} 7$ are represented in $\mathbf{A}$. Five of these mice recovered ( 3 of which remained euglycemic for more than 120 days and 1 of which was euglycemic for more than 150 days), and 2 mice remained diabetic. Five of the 10 mice treated with IgG are represented in $\mathbf{B}$, none of which recovered from diabetes. The transient reduction in blood glucose seen in some mice was likely to be related to exogenous insulin treatment. The difference between $2 \mathrm{H} 7$ - and IgG-treated mice was statistically significant $(P=0.03)$. (C) Three long-term anti-hCD20-treated euglycemic mice in $\mathbf{A}$ were challenged with glucose ( $1.5 \mathrm{mg} / \mathrm{g}$ body weight) i.p. Five newly NOD mice used as controls for dysfunctional islet $\beta$ cells also had an ipGTT performed, and their blood glucose levels before fasting were all above $300 \mathrm{mg} / \mathrm{dl}$. Five young NOD mice were used as controls for normal functional $\beta$ cells, and their blood glucose levels before fasting were between 93 and $121 \mathrm{mg} / \mathrm{dl}$.

Anti-hCD20 treatment suppressed antigen presentation of macrophages and splenic DCs. DCs and macrophages are APCs that play an important role in adaptive immune responses. To determine whether the depletion of B cells led to the functional modulation of these 2 types of APCs, we harvested peritoneal macrophages and splenic DCs and generated BM-derived DCs (BMDCs) from anti-hCD20 or control IgG-treated mice 1 month after treatment. Peritoneal macrophages or splenic DCs were used directly ex vivo whereas BMDCs were used after a 5- to 6-day culture in IL-4 and GM-CSF. Islet antigen-specific proliferation counts of BDC2.5 $\mathrm{CD} 4^{+}$ splenic $\mathrm{T}$ cells or insulin-specific $\mathrm{CD}^{+}$ $\mathrm{T}$ cell clones were used as readouts. As shown in Figure 9, removal of B cells significantly reduced antigen presentation function of macrophages (Figure 9A) and splenic DCs (Figure 9, B and C) in 2H7-treated mice to both $\mathrm{CD}^{+}$and $\mathrm{CD}^{+} \mathrm{T}$ cells. The reduction of antigen presentation was also accompanied by a reduction of IFN- $\gamma$ and IL-17 production (Figure 10, A and B). The suppression appeared to correlate with $\mathrm{B}$ cell depletion status, as the suppressed antigen presentation by macrophages or splenic DCs was no longer evident 6 months after anti-hCD20 treatment, when the mice had been completely repopulated with $\mathrm{B}$ cells for a long time (data not shown). As expected, removal of B cells by anti-hCD20 treatment did not alter the antigen presentation function of BMDCs (data not shown). The suppression appeared to be specific to antigen presentation function, as the same macrophages or DCs responded

IgG-treated mice, with a representative plot shown in Figure 8A. We also examined the expression of CTLA 4 on $\mathrm{CD}^{+}{ }^{+} \mathrm{T}$ cells and showed that $\mathrm{CD} 4{ }^{+} \mathrm{CTLA} 4^{+}$cells were also increased in anti-CD20treated mice compared with control IgG-treated mice (Figure 8B). Interestingly, a fraction of CD $4^{+} \mathrm{CTLA} 4^{+}$cells were not positive for CD25 (data not shown), suggesting that temporary removal of B cells may have induced 2 nonoverlapping populations of Tregs.

Increased frequency of transitional $B$ cells in regenerated $B$ cells after antibCD20 treatment. To investigate whether the repopulated B cells after anti-hCD20 treatment were different from the original B cells, we examined the phenotype of the regenerated $\mathrm{B}$ cells more than 4 months after anti-hCD20 treatment (when the B cell compartment was fully repopulated) compared with control mice. As shown in Supplemental Figure 7, newly generated B cell populations in anti-hCD20-treated mice had an increased frequency of $\mathrm{T} 2$ transitional B cells compared with age- and sex-matched control-treated mice. There was no striking difference in plasmablasts in the 2 groups (data not shown). well to microbial stimuli (poly I:C, LPS, and CpG), upregulated costimulatory molecules, and produced similar amounts of proinflammatory cytokines compared with macrophages or splenic DCs from IgG-treated mice (data not shown).

\section{Discussion}

To allow B cells to be depleted at specific time points and also to provide assessment of an agent similar to a B cell-depleting antibody already in clinical use in humans, we generated a transgenic NOD mouse that expresses hCD20 (hCD20/NOD). Expression of the hCD20 transgene did not cause any developmental or immunological adverse effects. However, hCD20 expression allowed us to deplete B cells using $2 \mathrm{H} 7$, an anti-hCD20 mAb that recognizes the same epitope as rituximab, at specific time points. Using this approach resulted in 3 significant findings. First, a single round of $\mathrm{B}$ cell depletion could prevent or delay full-blown diabetes. This was the case even when treatment was started after insulitis had begun. The effects of early B cell depletion could be detected long after B 
A

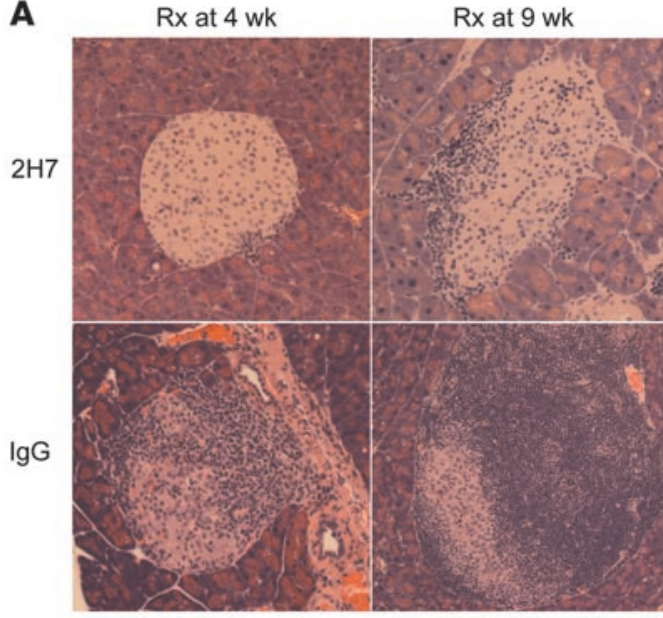

B

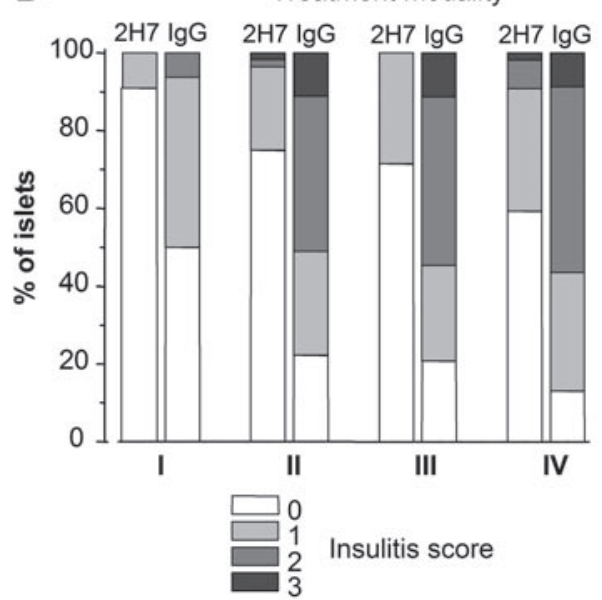

\section{Figure 6}

Histology and insulitis scores following $2 \mathrm{H} 7$ or IgG treatment. (A) Sections of pancreas illustrating islets taken from euglycemic hCD20/NOD mice at 2 months after treatment with $2 \mathrm{H} 7$ (top panels) or lgG antibody (lower panels) administered (Rx) at 4 weeks (left panels) or 9 weeks (right panels) of age. Magnification, $\times 100$. (B) The graph illustrates different insulitis scores following treatment: I, treatment at 4 weeks, observation 1 month after treatment; II, treatment at 4 weeks, observation 2 months after treatment; III, treatment at 9 weeks, observation 1 month after treatment; and IV, treatment at 9 weeks, observation 2 months after treatment. Islets were examined from at least 3 euglycemic mice in each group and insulitis scored in 16-56 islets. When the insulitis scores were compared between $2 \mathrm{H} 7$ and IgG treatment within each of the 4 groups, we found $P<0.0001$ for each group, which was statistically significant, correcting for multiple comparisons.

cells had returned. Second, and perhaps most relevant clinically, B cell depletion begun after frank hyperglycemia was effective in reversing diabetes in a significant fraction of animals. This reversal was also long lasting in the responding animals. Last, we identified an unexpected mechanism for the efficacy of B cell depletion - development of cells that could dominantly suppress disease induced by diabetogenic $T$ cells when these were transferred to a NOD/SCID recipient. Although the mechanisms by which B cells promote autoimmunity

\section{Figure 7}

Adoptive transfer of diabetes. (A) NOD/SCID mice were injected intravenously with (a) $10^{7}$ spleen cells from diabetic mice alone (closed circles); (b) $10^{7}$ spleen cells from diabetic mice cotransferred with spleen cells (107) from nondiabetic IgG-treated mice (open circles); (c) $10^{7}$ spleen cells from diabetic mice cotransferred with spleen cells $\left(10^{7}\right)$ from nondiabetic $2 \mathrm{H} 7$-treated mice (closed triangles); or (d) spleen cells $\left(10^{7}\right)$ from nondiabetic $2 \mathrm{H} 7$-treated mice alone (open squares). There was a significant delay in the onset of diabetes in the group cotransferred with cells from $2 \mathrm{H} 7$-treated mice $(P=0.007)$. The experiments were performed twice with similar results. Figure $7 \mathrm{~A}$ shows results of 1 of the 2 experiments. (B). NOD/SCID mice were injected intravenously with (a) $10^{7}$ spleen cells from diabetic mice alone (filled circles); (b) $10^{7}$ spleen cells from diabetic mice cotransferred with purified CD4 T cells $\left(3 \times 10^{6}\right)$ from nondiabetic $2 \mathrm{H} 7$-treated mice (open triangles); (c) $10^{7}$ spleen cells from diabetic mice cotransferred with purified splenic B cells $\left(3 \times 10^{6}\right)$ from nondiabetic $2 \mathrm{H} 7$-treated mice (open circles); (d) purified CD4 T cells $\left(3 \times 10^{6}\right)$ alone from nondiabetic $2 \mathrm{H} 7$-treated mice (closed squares); and (e) purified splenic B cells alone $\left(3 \times 10^{6}\right)$ from nondiabetic $2 \mathrm{H} 7$-treated mice (closed triangles). There was a significant delay in the onset of diabetes in the group cotransferred with $\mathrm{CD}^{+}{ }^{+} \mathrm{T}$ cells from $2 \mathrm{H} 7$-treated mice compared with spleen cells from diabetic mice alone $(P=0.029)$ and in the group cotransferred with purified splenic $B$ cells compared with spleen cells from diabetic mice alone $(P=0.029)$. There was no statistical significance between the groups cotransferred with $\mathrm{CD} 4^{+} \mathrm{T}$ cells or $\mathrm{B}$ cells $(P=0.28)$. The results shown in Figure 7B were from 1 of the 2 sets of experiments.
- and therefore the mechanisms by which $\mathrm{B}$ cell depletion treats autoimmunity - have been much discussed (23, 36-38), we believe this is the first demonstration that $\mathrm{B}$ cell depletion promotes regulatory cell development. This latter finding thus provides an important conceptual advance and opens an area of research into how B cell depletion operates to treat a wide variety of autoimmune diseases.

Depleting B cells at early stages of disease was effective in delaying disease in a long-lasting fashion, thus formally excluding altered
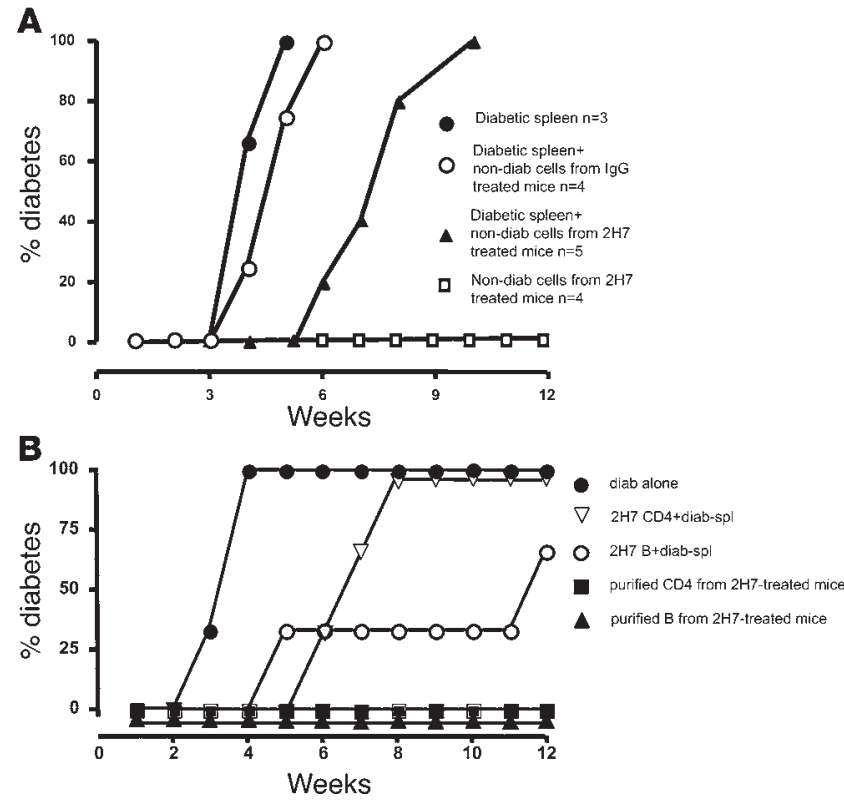
A

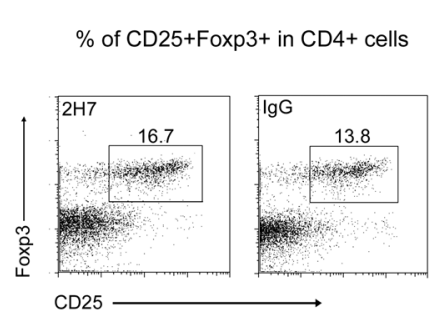

B

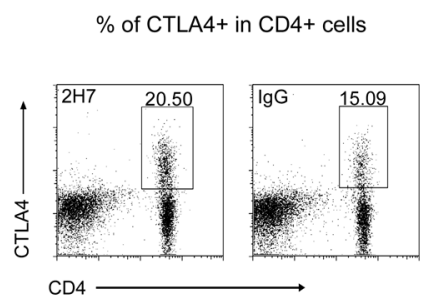

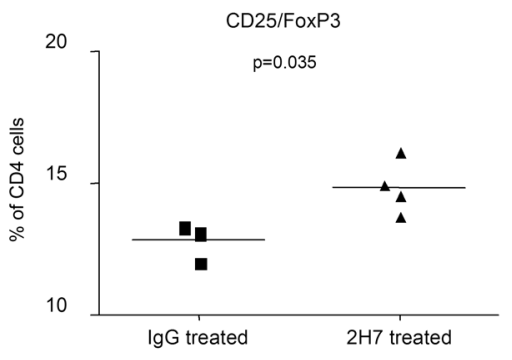
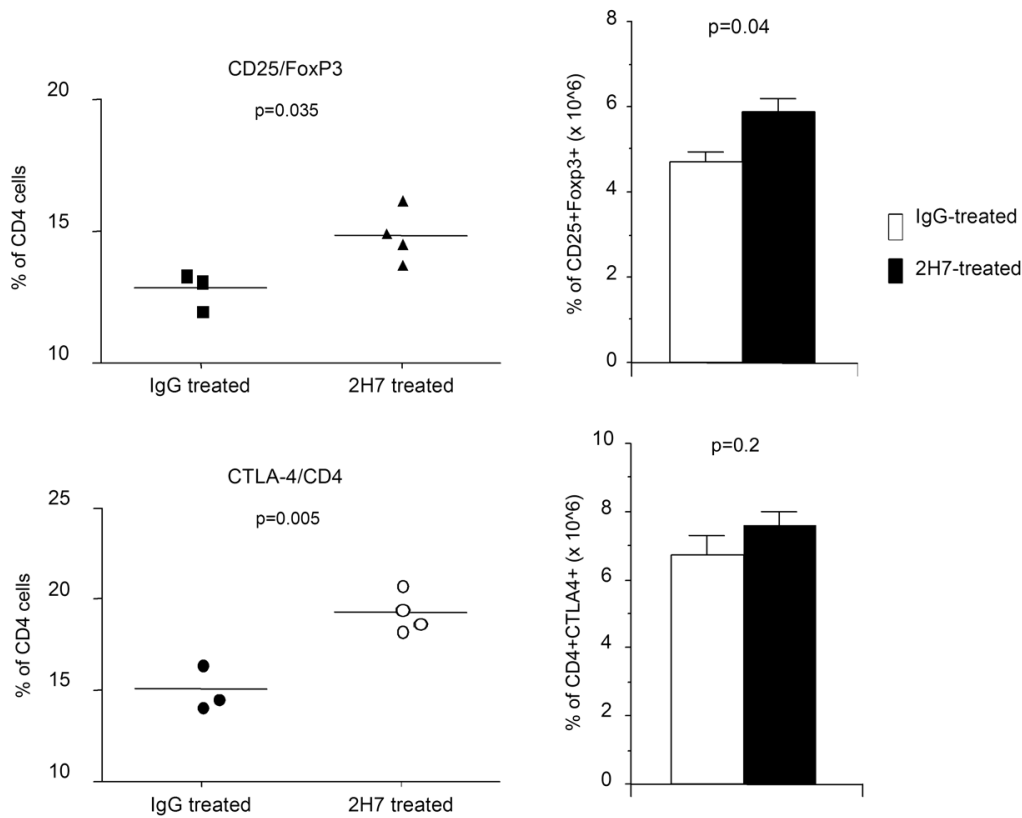

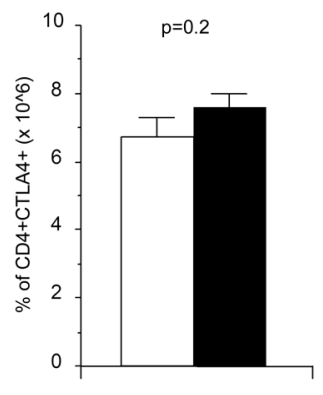

Figure 8

2H7-treated hCD20 mice have increased CD4 T cells expressing regulatory markers. (A) Splenocytes from hCD20 mice, treated at 9 weeks of age with $2 \mathrm{H} 7$ or IgG, were stained with anti-CD4, anti-CD25, and anti-Foxp3 antibodies. A representative flow cytometric plot is illustrated, and percentages shown in the gate represent the Foxp $3^{+} \mathrm{CD} 25^{+}$cells as a percentage of total CD4 T cells. The graph in the middle is a summary of the values obtained from a number of mice. The graph on the right is a summary of the absolute number of $\mathrm{CD} 4^{+} \mathrm{CD} 25^{+} \mathrm{FoxP} 3^{+} \mathrm{T}$ cells. (B). Splenocytes from hCD20 mice, treated at 9 weeks of age with $2 \mathrm{H} 7$ or IgG, were stained with anti-CD4 and CTLA4. The percentages shown in the gate represent the CTLA4+ cells as a percentage of total CD4 T cells. The graph in the middle illustrates the values obtained from a number of mice. The graph on the right is a summary of the absolute number of $\mathrm{CD} 4^{+} \mathrm{CTLA} 4^{+} \mathrm{T}$ cells.

lymphoid architecture development as an explanation for the lack of diabetes in mutant mice genetically lacking B cells from birth. B cells returned to predepletion levels within 3 months of the initiation of the treatment and were present at substantial levels within weeks, yet the disease incidence curve lagged behind controls for months and possibly indefinitely. This suggested that temporary $\mathrm{B}$ cell depletion altered the status of cells that may interact with B cells. As discussed below, this in part stimulated experiments to detect dominant regulatory cells that may emerge in the absence of B cells, although at this stage it is unclear whether they have a direct effect on B cells upon their reconstitution. Nevertheless, the repopulated splenic B cells had increased frequency of T2 transitional B cells and decreased frequency of marginal zone B cells, and this warrants further investigation.

Importantly, temporary removal of B cells after disease onset could reverse diabetes in over one-third of mice, with responding mice becoming euglycemic for a prolonged period of time. The ability to rescue mice that had already become hyperglycemic and thus had advanced islet cell destruction suggests that regulatory cells not only prevent activation and/or migration of islet-specific T cells but also reduce pathogenicity of $\mathrm{T}$ cells that had already infiltrated islets. In any case, the approach is clinically relevant as it indicates that treatment during the honeymoon period could have long-term effects. Although we induced sustained remission in one-third of mice with frank hyperglycemia, the ultimately achievable success rate may be higher than in these initial studies, provided that treatment initiation time and supportive care of the mice awaiting remission were optimized, such as initiation of the treatment on the day of diagnosis and implantation of insulin pellets to better control blood glucose. In this regard, our approach was conservative in that we waited for repeated hyperglycemia; thus, it is highly possible that the mice we treated had more advanced $\beta$ cell destruction than in some other studies $(39,40)$. It is difficult to titrate the best insulin support in mice due to constant food access. However, in people, detection of subclinical hyperglycemia in at-risk populations could be achievable, and optimal insulin therapy during initial hyperglycemia is routine. Nonetheless, even if only one-third of patients were provided a sustained remission by this intervention, this would be important. The main conclusion is that even without best control of blood glucose and with a stringent definition of diabetes, remission can be achieved with B cell depletion.

It was intriguing that reversal of diabetes in some mice occurred over a protracted and variable length of time, from 2 to 6 weeks after the initiation of treatment. This could reflect the time needed for effector cells to run their course, for suppressor cell induction (see below), and/or for the regeneration or restoration of function of $\beta$ cells. The length of time was also possibly dependent on the number of islets already destroyed by the time that diabetes manifested.

Perhaps the most significant and surprising finding was that induction of long-lasting remission is likely to be mediated by the development of dominant regulatory cells. This is indicated by the clear identification of such an effect in our cotransfer system. Cells from hCD20/NOD mice that had received $2 \mathrm{H} 7$ treatment 6 to 7 months earlier and that remained nondiabetic long after full B cell reconstitution significantly delayed the induction of diabetes by spleen cells from NOD mice upon transfer into NOD/SCID recipi- 


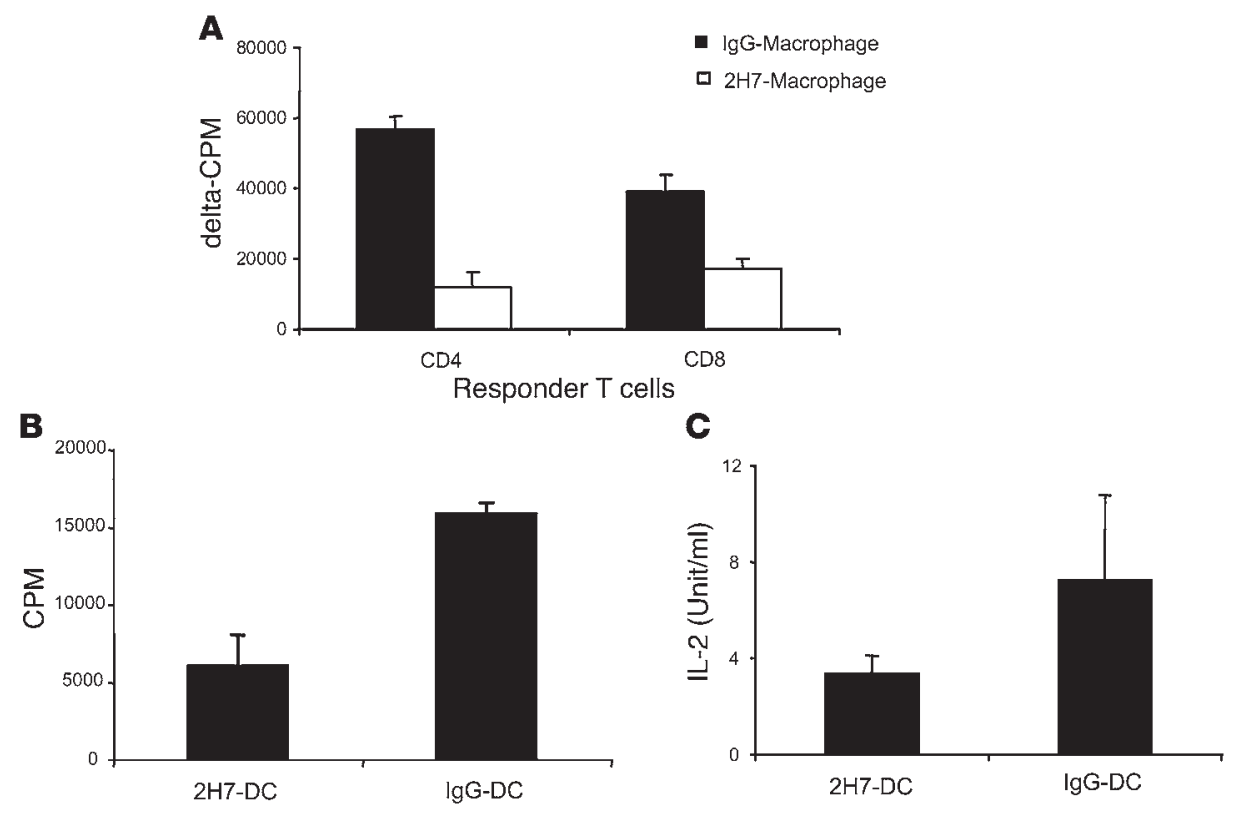

Figure 9

Antigen presentation of antigenic peptides to islet autoantigen-specific T cells. (A) Peritoneal macrophages were harvested from hCD20/NOD mice 1 month after $2 \mathrm{H} 7$ or IgG treatment and used as APCs after irradiation in a proliferation assay with BDC2.5 CD4 cells responding to BDC2.5 mimotope or 6426 cloned CD8 T cells responding to 9-mer insulin B chain peptide of amino acid position 15-23 (B15-B23). ${ }^{3 \mathrm{H}}$-thymidine incorporation is presented as $\Delta \mathrm{cpm}$ (cpm in the presence of antigenic peptide minus cpm in the absence of antigenic peptide). Macrophages from $2 \mathrm{H} 7$-treated mice presented peptides poorly to both CD4 and CD8 T cells compared with macrophages from IgG-treated mice $(P<0.005)$. (B) One month after $2 \mathrm{H} 7$ or lgG treatment, splenic CD11 $\mathrm{c}^{+}$DCs of hCD20/NOD mice were used as APCs after irradiation. 6426 CD8 cloned T cells were cultured with irradiated DCs in the presence or absence of 9-mer insulin B chain peptide of amino acid position 15-23 (B15-B23) (at 3 $\mu \mathrm{g} / \mathrm{ml})$ in a ${ }^{3} \mathrm{H}$-thymidine incorporation proliferation assay. (C) Splenic CD11 $c^{+}$DCs were purified from hCD20/NOD mice 1 month after $2 \mathrm{H} 7$ or lgG treatment and used as APCs after irradiation. Purified splenic BDC2.5 CD4 T cells were cultured with irradiated DCs in the presence or absence of BDC2.5 mimotope. IL-2 production was measured by cytotoxic T lymphocyte line (CTLL) assay in culture supernatants after a 48-hour incubation.

ents. In essence, this demonstrates that depletion of B cells unexpectedly can induce a state of transferable immune tolerance. We believe this is a novel mechanism of action for B cell depletion.

With regard to $T$ cells, as we found the expansion of 2 populations of $\mathrm{T}$ cells known to regulate autoimmunity in other settings $\left(\mathrm{CD} 4{ }^{+} \mathrm{CD} 25^{+} \mathrm{Foxp}^{+}\right.$as well as $\mathrm{CD} 4^{+} \mathrm{CTLA} 4^{+}$cells), we speculate that one or both of these populations may contain the important cells. How the depletion of B cells leads to development of Tregs is not yet known, but it may relate to alteration in the balance of cells that present antigen to islet-specific T cells. In the absence of B cells, both peripheral macrophages and DCs may play a more dominant role, ultimately leading to quiescence rather than inflammation, as suggested by the decreased presentation ability of peritoneal macrophages and splenic DCs derived from B cell-depleted animals. This effect might be short-circuited in the presence of expanding clones of self-reactive B cells when the B cell compartment is intact. This is currently under further investigation.

Surprisingly, in addition to Tregs, we found that B cells could also mediate dominant suppression upon cotransfer with diabetogenic T cells. The newly reconstituted B cell population had a more than 2-fold increase in T2 transitional B cells and nearly a 2 -fold decrease in marginal zone B cells. Furthermore, there was decreased frequency of anti-islet autoantibodies. The obligatory role of $B$ cells in activating autoreactive T cells in NOD mice, as shown in B cell-deficient knockouts as well as in this paper, implies that there are important $\mathrm{B}$ cell-T cell interactions in vivo. This is supported by the observation that cured hCD20/NOD mice showed reduced $\mathrm{T}$ cell responses to glutamic acid decarboxylase autoantigen (data not shown). It is thus logical to assume that B cells from previously treated mice could conversely assert regulatory function in the same types of B cell- $\mathrm{T}$ cell interactions. There are a number of reports of regulatory B cells with powerful effects, in part mediated via IL-10, in inflammatory bowel disease and collagen-induced arthritis, although regulatory B cells have not previously been implicated in diabetes in NOD mice (41-43). How regulatory $\mathrm{B}$ cells develop during reconstitution is a very interesting unresolved question. Regulatory $\mathrm{T}$ cells and $\mathrm{B}$ cells could influence each other (44). Alternatively, newly developing B cells that emerge in a noninflammatory environment, enforced by the treatment itself, may be more likely to adopt a regulatory phenotype. In this context, there appears to be a window of pancreatic development in which $\beta$ cells undergo apoptosis and which is critical for disease initiation (45); reconstituted B cells with regulatory activity would have developed after this window. We have not yet characterized the identity of the regulatory B cells. In other systems, regulatory B cells are enriched among immature B cell populations (46), and it may not be coincidental that after regeneration, immature phenotype $B$ cells are more frequent in our mice and also in SLE patients who had undergone rituximab treatment (47). An implication of our findings for therapeutic design is that continuous $\mathrm{B}$ cell depletion may not be desirable, as eventually, regulatory B cells could also be depleted. Instead, depletion may best be carried out in cycles, monitoring for increased disease activity and then depleting B cells again if their proinflammatory influence begins to exceed their regula- 
A

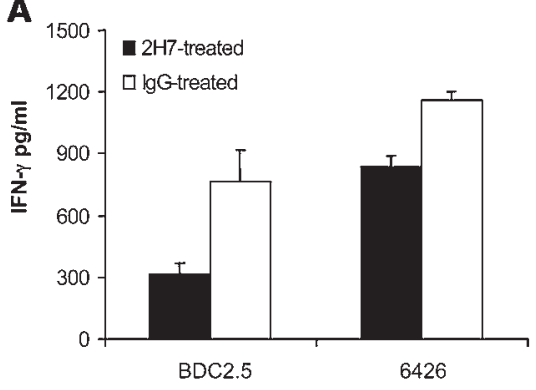

\section{Figure 10}

Suppressed IFN- $\gamma$ and IL-17 production by diabetogenic CD4 or CD8 T cells. (A) Peritoneal macrophages were harvested from hCD20/NOD mice 1 month after $2 \mathrm{H} 7$ or IgG treatment and used as APCs after irradiation. Purified splenic BDC2.5 CD4 T cells or 6426 CD8 cloned $T$ cells were cultured with irradiated macrophages in the presence or absence of BDC2.5 mimotope and 9-mer insulin B chain peptide of amino acid position 15-23 (B15-B23) (both at $3 \mu \mathrm{g} / \mathrm{ml}$ ), respectively. IFN- $\gamma$ was measured in culture supernatants after a 72 -hour incubation. (B) Peritoneal macrophages or splenic CD11 $\mathrm{c}^{+}$DCs from hCD20/NOD mice 1 month after $2 \mathrm{H} 7$ or IgG treatment were purified as described. Purified splenic BDC2.5 CD4 T cells were cultured with irradiated macrophages or splenic DCs in the presence or absence of BDC2.5 mimotope. IL-17 was measured in culture supernatants after a 72-hour incubation.

tory component. In addition, if regulatory B cells turn out to have unique phenotypes, it may eventually be possible to design therapies to spare them during depletion or to artificially reconstitute them. In any case, because anti-hCD20 treatment induces different regulatory cells, such as Tregs and regulatory B cells, as well as inhibits APC function of macrophages and DCs, the tolerant state is likely to be a result of complex interactions, and there could be both redundancy and dependency. Further dissection of this state will require a variety of experiments and approaches, which is the subject of our current work.

In conclusion, we have shown that depleting B cells at different time points delayed and/or reduced the onset of diabetes and reversed diabetes in over one-third of mice. Although a most unexpected aspect of our findings was that mice depleted of B cells harbor dominant regulatory cells, the efficacy of B cell depletion therapy, overall, is likely to stem from a combination of both a decrease in effector CD4 and/or CD8 T cells and induction of such regulatory cells. It is possible that reduction or alteration of effector cell activation by acute B cell depletion then sets the stage for regulatory cell development or expansion, thus sustaining the remission even after B cells return. Moreover, another important finding is that $\mathrm{B}$ cells are among the regulatory populations. Our results complement and substantially extend earlier studies that indicated that B cells play an important role in the pathogenesis of autoimmune diabetes and bolster the notion that targeting $\mathrm{B}$ cells may be a useful therapeutic strategy for patients with new-onset T1D. Although it is encouraging that a single cycle of B cell depletion led to a durable response, it is possible that further treatment would lead to longer and possibly even indefinite remissions.

\section{Methods}

Mice. We have made hCD20-transgenic mice using bacterial artificial chromosomes incorporating the hCD20 locus (30). To generate hCD20-transgenic NOD mice, we backcrossed the founder line to NOD/Caj mice over 10 generations. The expression of hCD20 allowed the use of a murine antihCD20 antibody (2H7) that recognizes the same epitope as rituximab to target $\mathrm{B}$ cells that are subsequently deleted.
NOD/Caj and NOD/SCID mice have been maintained at Yale University for nearly 20 years. All the mice were kept in specific pathogen-free conditions in a 12-hour dark/light cycle and housed in individually ventilated filter cages with autoclaved food. The use of the animals and the procedures applied in this study were in accordance with the current National Research Council Guide for the Care and Use of the Laboratory Animals and were approved by the Institutional Animal Care and Use Committee of Yale University.

Antibodies and reagents. All fluorochrome-conjugated mAbs used in this study were purchased from eBioscience. All the hybridoma supernatants containing different mAbs, used for cell purification, were generously provided by Kim Bottomly (Yale University). Affinity-purified anti-hCD20 monoclonal antibody $2 \mathrm{H} 7$, recognizing the same epitope as rituximab (a humanized anti-hCD20 $\mathrm{mAb}$ ), was prepared as described recently (30) and by BioExpress from the hybridoma cell line $2 \mathrm{H} 7$. Control IgG used in the in vivo studies was purchased from Rockland. Magnetic beads conjugated with goat anti-mouse IgG, goat anti-mouse IgM, or goat anti-rat IgG were purchased from QIAGEN. Bruff's medium and heat-inactivated FCS were purchased from Invitrogen and Gemini, respectively.

BDC2.5 mimotope and 9-mer insulin B chain peptide of amino acid position 15-23 (B15-B23) were synthesized at the Keck facility of the Yale University School of Medicine. The sequences of BDC2.5 mimotope and 9-mer insulin B chain peptide of amino acid position 15-23 (B15-B23) are RTRPLWVRME and LYLVCGERG, respectively.

$B$ and T cell purification. B cells were isolated using the MACS cell isolation kits following the manufacturer's instructions (Miltenyi Biotech). In some experiments, B cells were also isolated by negative selection to remove $\mathrm{T}$ cells and macrophages (F4/80) with magnetic beads. CD4 T cells were purified by removing $\mathrm{CD} 8^{+} \mathrm{T}$ cells, B cells, and $\mathrm{MHC}$ class $\mathrm{II}^{+}$cells using monoclonal antibodies and magnetic beads. The purity of the cells was routinely approximately $90 \%$, analyzed by FACS.

$B$ cell stimulation. Splenocytes were harvested from hCD20 mice and nontransgenic NOD littermates and stimulated overnight with anti-mouse CD40 mAb (FGK45 supernatant) or purified anti-mouse Ig (SigmaAldrich) at different concentrations. The cells were then washed and stained with B220 together with anti-CD86 or anti-CD40 (HM40-3, eBioScience) and analyzed by flow cytometry.

$B M D C$ s, splenic DCs, and peritoneal macrophages. BM cells were flushed from the femurs and tibiae of $2 \mathrm{H} 7$ - or IgG-treated mice. BM cells were depleted of red cells and cultured in Bruff's medium (Invitrogen) with 5\% FCS in the presence of GM-CSF ( $1 \%$ supernatant from J558L cells transfected with mouse GM-CSF construct) and recombinant IL-4 (100 U/ml). The culture medium was replenished every 2 days. On day 5 or 6 , nonadherent and loosely adherent cells were harvested. These cells contained approximately $70 \% \mathrm{CD} 11 \mathrm{c}^{+}$ DCs by FACS analysis and were used as BMDCs. CD $11 \mathrm{c}^{+} \mathrm{DCs}$ derived from spleen were purified using a kit from Miltenyi according to the manufacturer's instructions and used immediately in the assays. Peritoneal macrophages were harvested by flushing mouse peritoneal cavity with ice-cold PBS. They usually contained approximately $70 \% \mathrm{CD} 1 \mathrm{~b}^{+}$cells and were used freshly ex vivo.

Antigen presentation assay. MACS bead-purified BDC2.5 splenic $\mathrm{CD} 4^{+} \mathrm{T}$ cells $\left(10^{5} /\right.$ well $)$ from BDC2.5 TCR-transgenic mice and insulin-reactive CD8 ${ }^{+}$ T cell clone, 6426 cells $(48)\left(2 \times 10^{4} /\right.$ well $)$ were cultured in the presence or absence of BDC2.5 mimotope and 9-mer insulin B chain peptide of amino 
acid position 15-23 (B15-B23) at $3 \mu \mathrm{g} / \mathrm{ml}$, respectively (in Bruff's medium containing $5 \% \mathrm{FCS})$ with irradiated (30 Gy) BMDCs $\left(2 \times 10^{4} /\right.$ well) or splenic DCs $\left(2 \times 10^{4} /\right.$ well $)$ or macrophages $\left(5 \times 10^{4}\right.$ or $2 \times 10^{4} /$ well $)$. The APCs were used from the mice 1 month after the $2 \mathrm{H} 7$ or IgG control treatment.

$\mathrm{T}$ cell proliferation to the antigenic peptide, assessed by ${ }^{3} \mathrm{H}$-thymidine incorporation during the last 14 to 18 hours in the 3 -day culture, was used as a measure of antigen presentation. The culture supernatants were tested for production of IL-2, IFN- $\gamma$, and IL-17.

Detection of islet autoantibodies. Anti-insulin autoantibodies were detected using Luminex beads covalently conjugated with human insulin, following the protocol provided by the manufacturer (Bio-Rad). Control beads were conjugated with BSA. Of each serum sample, $3 \mu \mathrm{l}$ was mixed with $35 \mu \mathrm{l}$ assay buffer (Invitrogen). Each sample was divided equally into the appropriate number of wells of two 96-well plates. Free insulin was added to the samples in 1 plate at a final concentration of $30 \mu \mathrm{g} / \mathrm{ml}$ (insulin block), and an equivalent volume of assay buffer was added to the other plate. All samples were incubated for 5-10 minutes at room temperature on a shaking platform. Beads conjugated with insulin or BSA (500-1000 each/assay) were mixed together, then aliquoted into the appropriate number of wells of 2 Luminex filter plates (Millipore). Liquid was removed by vacuum suction, and insulin-blocked or nonblocked serum samples were added to the wells of the 2 filter plates. These were further incubated for 3 hours, with shaking, at room temperature. The liquid was removed, and $30 \mu \mathrm{l}$ of a 1:200 dilution of goat anti-mouse (biotin-conjugated) antibody (Invitrogen) was added to each well. After 15 minutes incubation with shaking at room temperature, Streptavidin-PE ( $5 \mu \mathrm{g} / \mathrm{ml}$ final dilution) was added for 10 minutes for detection, followed by liquid removal. Beads were resuspended in $130 \mu \mathrm{l}$ Luminex buffer/well. Plates were read in a Luminex reader. Validation of this Luminex assay was carried out with known anti-insulin positive NOD serum samples that were kindly provided by George Eisenbarth (Barbara Davis Center for Childhood Diabetes, Denver, Colorado, USA).

Natural history of diabetes development. NOD and hCD20/NOD mice were observed for diabetes development by weekly screening for glycosuria. Diabetes was confirmed by blood glucose greater than $250 \mathrm{mg} / \mathrm{dl}(13.9 \mathrm{mmol} / \mathrm{l})$ for 2 consecutive readings.

$B$ cell depletion and its effect on spontaneous diabetes development. B lymphocytes were depleted by injecting the hCD20-transgenic NOD mice (hCD20/ NOD) with the anti-hCD20 mAb, $2 \mathrm{H} 7$, i.v. One cycle of treatment was used in all the studies presented here, which was a 9-day treatment protocol: $0.5 \mathrm{mg} /$ mouse for the first injection (day 0) followed by 3 injections of $0.25 \mathrm{mg} /$ mouse at 3-day intervals. Purified mouse IgG was used as a control antibody. To test the effect of temporary depletion of $\mathrm{B}$ cells on the initiation and progression of spontaneous diabetes, 3 groups of hCD20/ NOD mice were used: preinsulitic (4 weeks old); prediabetic (9 weeks old), and new-onset diabetic mice were treated with $2 \mathrm{H} 7 \mathrm{mAb}$. The same age groups were also treated with mouse IgG as controls. All the treated mice were observed for diabetes development to 35 weeks.

Adoptive transfer experiments. NOD/SCID mice (between 5-7 weeks of age) were used as recipients in adoptive transfer experiments. Diabetic
NOD splenocytes $\left(10^{7}\right)$ were injected i.v. with (a) total splenocytes $\left(10^{7}\right)$, (b) purified $\mathrm{CD}^{+} \mathrm{T}$ cells $\left(3 \times 10^{6}\right)$, and $(\mathrm{c})$ purified B cells $\left(3 \times 10^{6}\right)$ from nondiabetic anti-hCD20 mAb-treated transgenic mice. Diabetic NOD splenocytes $\left(10^{7}\right)$ alone, splenocytes $\left(10^{7}\right)$ from nondiabetic anti-hCD20 $\mathrm{mAb}$-treated transgenic mice alone, purified $\mathrm{CD} 4^{+} \mathrm{T}$ cells $\left(3 \times 10^{6}\right)$ from anti-hCD20 mice alone, or purified B cells $\left(3 \times 10^{6}\right)$ from anti-hCD20 mice alone were transferred into NOD/SCID mice as controls. NOD/SCID mice transferred with splenocytes from IgG-treated nondiabetic hCD20/NOD mice together with diabetic NOD splenocytes were also used as controls, all at $10^{7}$ cells per mouse. All the recipients were monitored for glycosuria weekly after adoptive transfer, and the experiments were terminated 3 months after transfer unless the mice developed diabetes, which was confirmed by blood glucose greater than $250 \mathrm{mg} / \mathrm{dl}(13.9 \mathrm{mmol} / \mathrm{l})$.

ipGTT. Mice were fasted overnight (free water access but no food) before challenge (i.p.) with glucose ( $1.5 \mathrm{mg} / \mathrm{g}$ body weight). The levels of blood glucose were measured using a OneTouch-UltraSmart glucose meter at different time points: before fasting; prior to glucose challenge; and 15, 30, 60, 90, and 120 minutes after glucose challenge.

Histopathology and insulitis score. Pancreata were fixed in buffered formalin. Paraffin-embedded tissues were sectioned and stained with H\&E. Insulitis was scored under light microscopy using the following grading: 0 , no insulitis; 1 , peri-insulitis and insulitis involving less than $25 \%$ islet; 2 , insulitis involving more than $25 \%$ islet; 3 , more than $75 \%$ to complete islet infiltration.

Statistics. Incidence of diabetes was compared using the log-rank test. Insulitis scores were compared by $\chi^{2}$ test. Mean values of cell measurements by flow cytometry were compared by unpaired Student's $t$ tests. Statistical analysis was performed using GraphPad Prism software.

\section{Acknowledgments}

We thank Bin Lu for expert animal care and Kevan Herold for critical reading of the manuscript. This project was funded by a JDRF Innovative Research grant (5-2006-121), a Seaver Institute research grant, NIH grant R01-AR44077, and the Animal and Genetics Core of Yale DERC (P30-DK-45735). F.S. Wong was a Wellcome Trust Senior Fellow in Clinical Science. A. Ahuja was supported by the Arthritis Foundation.

Received for publication April 16, 2007, and accepted in revised form September 12, 2007.

Address correspondence to: Li Wen, Section of Endocrinology, Department of Internal Medicine, Yale School of Medicine, 330 Cedar Street, New Haven, Connecticut 06520, USA. Phone: (203) 785-7186; Fax: (203) 737-5558; E-mail: li.wen@yale.edu.

Daniel Rodriguez-Pinto's present address is: Department of Autoimmune Diseases, The Feinstein Institute for Medical Research, Manhasset, New York, USA.
1. Serreze, D.V., et al. 1996. B lymphocytes are essential for the initiation of $\mathrm{T}$ cell-mediated autoimmune diabetes: analysis of a new "speed congenic" stock of NOD.Ig mu null mice. J. Exp. Med. 184:2049-2053.

2. Wong, F.S., et al. 1998. The role of lymphocyte subsets in accelerated diabetes in nonobese diabeticrat insulin promoter-B7-1 (NOD-RIP-B7-1) mice. J. Exp. Med. 187:1985-1993.

3. Noorchashm, H., et al. 1997. B-cells are required for the initiation of insulitis and sialitis in nonobese diabetic mice. Diabetes. 46:941-946.

4. Wong, F.S., and Wen, L. 2005. B cells in autoim- mune diabetes. Rev. Diabet. Stud. 2:121-135.

5. Yu, L., et al. 2000. Early expression of antiinsulin autoantibodies of humans and the NOD mouse: evidence for early determination of subsequent diabetes. Proc. Natl. Acad. Sci. U. S. A. 97:1701-1706.

6. Baekkeskov, S., et al. 1990. Identification of the $64 \mathrm{~K}$ autoantigen in insulin-dependent diabetes as the GABA-synthesizing enzyme glutamic acid decarboxylase. Nature. 347:151-156.

7. Hawkes, C.J., Wasmeier, C., Christie, M.R., and Hutton, J.C. 1996. Identification of the 37-kDa antigen in IDDM as a tyrosine phosphatase-like protein (phogrin) related to IA-2. Diabetes. 45:1187-1192.
8. Solimena, M., et al. 1996. ICA 512, an autoantigen of type I diabetes, is an intrinsic membrane protein of neurosecretory granules. EMBOJ. 15:2102-2114.

9. Beyan, H., Ola, T., David, R., and Leslie, G. 2006 Progression of autoimmune diabetes: slowly progressive insulin-dependent diabetes mellitus or latent autoimmune diabetes of adult. Ann. N. Y. Acad. Sci. 1079:81-89.

10. Wasserfall, C.H., and Atkinson, M.A. 2006. Autoantibody markers for the diagnosis and prediction of type 1 diabetes. Autoimmun. Rev. 5:424-428.

11. Miao, D., Yu, L., and Eisenbarth, G.S. 2007. Role of autoantibodies in type 1 diabetes. Front. Biosci. 
12:1889-1898.

12. Gardner, S.G., et al. 1999. Progression to diabetes in relatives with islet autoantibodies. Is it inevitable? Diabetes Care. 22:2049-2054.

13. Akashi, T., et al. 1997. Direct evidence for the contribution of $\mathrm{B}$ cells to the progression of insulitis and the development of diabetes in non-obese diabetic mice. Int. Immunol. 9:1159-1164.

14. Falcone, M., Lee, J., Patstone, G., Yeung, B., and Sarvetnick, N. 1998. B lymphocytes are crucial antigen-presenting cells in the pathogenic autoimmune response to GAD65 antigen in nonobese diabetic mice. J. Immunol. 161:1163-1168.

15. Serreze, D.V., et al. 1998. B lymphocytes are criti$\mathrm{cal}$ antigen-presenting cells for the initiation of $\mathrm{T}$ cell-mediated autoimmune diabetes in nonobese diabetic mice. J. Immunol. 161:3912-3918.

16. Hulbert, C., Riseili, B., Rojas, M., and Thomas, J.W. 2001. B cell specificity contributes to the outcome of diabetes in nonobese diabetic mice. J. Immunol. 167:5535-5538.

17. Serreze, D.V., and Silveira, P.A. 2003. The role of B lymphocytes as key antigen-presenting cells in the development of T cell-mediated autoimmune type 1 diabetes. Curr. Dir. Autoimmun. 6:212-227.

18. Wong, F.S., et al. 2004. Investigation of the role of Bcells in type 1 diabetes in the NOD mouse. Diabetes. 53:2581-2587.

19. Tian, J., Zekzer, D., Lu, Y., Dang, H., and Kaufman, D.L. 2006. B cells are crucial for determinant spreading of $\mathrm{T}$ cell autoimmunity among beta cell antigens in diabetes-prone nonobese diabetic mice. J. Immunol. 176:2654-2661.

20. Greeley, S.A., et al. 2002. Elimination of maternally transmitted autoantibodies prevents diabetes in nonobese diabetic mice. Nat. Med. 8:399-402.

21. Rastetter, W., Molina, A., and White, C.A. 2004. Rituximab: expanding role in therapy for lymphomas and autoimmune diseases. Annu. Rev. Med. 55:477-503.

22. Martin, F., and Chan, A.C. 2004. Pathogenic roles of B cells in human autoimmunity; insights from the clinic. Immunity. 20:517-527.

23. Martin, F., and Chan, A.C. 2006. B cell immunobiology in disease: evolving concepts from the clinic.
Annu. Rev. Immunol. 24:467-496.

24. Johnson, P., and Glennie, M. 2003. The mechanisms of action of rituximab in the elimination of tumor cells. Semin. Oncol. 30:3-8.

25. Edwards, J.C., Leandro, M.J., and Cambridge, G. 2005. B lymphocyte depletion in rheumatoid arthritis: targeting of CD20. Curr. Dir. Autoimmun. 8:175-192.

26. Edwards, J.C., et al. 2004. Efficacy of B-cell-targeted therapy with rituximab in patients with rheumatoid arthritis. N. Engl. J. Med. 350:2572-2581.

27. Kneitz, C., Wilhelm, M., and Tony, H.P. 2002. Effective $\mathrm{B}$ cell depletion with rituximab in the treatment of autoimmune diseases. Immunobiology. 206:519-527.

28. Uchida, J., et al. 2004. The innate mononuclear phagocyte network depletes B lymphocytes through $\mathrm{Fc}_{\mathrm{C}}$ receptor-dependent mechanisms during anti-CD20 antibody immunotherapy. J. Exp. Med. 199:1659-1669.

29. Hamaguchi, Y., Xiu, Y., Komura, K., Nimmerjahn, F., and Tedder, T.F. 2006. Antibody isotype-specific engagement of Fcgamma receptors regulates B lymphocyte depletion during CD20 immunotherapy. J. Exp. Med. 203:743-753.

30. Ahuja, A., Shupe, J., Dunn, R., Kashgarian, M., Kehry, M., and Shlomchik, M. 2007. Depletion of $\mathrm{B}$ cells in murine lupus: efficacy and resistance. J. Immunol. 179:3351-3361.

31. Hamaguchi, Y., et al. 2005. The peritoneal cavity provides a protective niche for $\mathrm{B} 1$ and conventional B lymphocytes during anti-CD20 immunotherapy in mice. J. Immunol. 174:4389-4399.

32. Du, W., et al. 2006. TGF-beta signaling is required for the function of insulin-reactive $T$ regulatory cells. J. Clin. Invest. 116:1360-1370.

33. Hori, S., Nomura, T., and Sakaguchi, S. 2003. Control of regulatory $T$ cell development by the transcription factor Foxp3. Science. 299:1057-1061.

34. Fontenot, J.D., Gavin, M.A., and Rudensky, A.Y. 2003. Foxp3 programs the development and function of CD4+CD25+ regulatory T cells. Nat. Immunol. 4:330-336.

35. Khattri, R., Cox, T., Yasayko, S.A., and Ramsdell, F. 2003. An essential role for Scurfin in CD 4+CD25+ T regulatory cells. Nat. Immunol. 4:337-342.
36. Shlomchik, M.J., Craft, J.E., and Mamula, M.J. 2001. From $\mathrm{T}$ to $\mathrm{B}$ and back again: positive feedback in systemic autoimmune disease. Nat. Rev. Immunol. 1:147-153.

37. Tuscano, J.M., Harris, G.S., and Tedder, T.F. 2003. B lymphocytes contribute to autoimmune disease pathogenesis: current trends and clinical implications. Autoimmun. Rev. 2:101-108.

38. Dorner, T. 2006. Crossroads of B cell activation in autoimmunity: rationale of targeting B cells. J. Rheumatol. Suppl. 77:3-11.

39. Sherry, N.A., et al. 2006. Effects of autoimmunity and immune therapy on beta-cell turnover in type 1 diabetes. Diabetes. 55:3238-3245.

40. Sherry, N.A., et al. 2007. Exendin-4 improves reversal of diabetes in NOD mice treated with anti-CD3 $\mathrm{mAb}$ by enhancing recovery of $\{$ beta\} cells. Endocrinology. 148:5136-5144.

41. Fillatreau, S., Sweenie, C.H., McGeachy, M.J., Gray, D., and Anderton, S.M. 2002. B cells regulate autoimmunity by provision of IL-10. Nat. Immunol. 3:944-950.

42. Mauri, C., Gray, D., Mushtaq, N., and Londei, M. 2003. Prevention of arthritis by interleukin 10-producing B cells. J. Exp. Med. 197:489-501.

43. Mizoguchi, A., and Bhan, A.K. 2006. A case for regulatory B cells. J. Immunol. 176:705-710.

44. Mann, M.K., Maresz, K., Shriver, L.P., Tan, Y., and Dittel, B.N. 2007. B cell regulation of CD4+CD25+ $T$ regulatory cells and IL-10 via B7 is essential for recovery from experimental autoimmune encephalomyelitis. J. Immunol. 178:3447-3456.

45. Mathis, D., Vence, L., and Benoist, C. 2001. betaCell death during progression to diabetes. Nature. 414:792-798.

46. Evans, J.G., et al. 2007. Novel suppressive function of transitional $2 \mathrm{~B}$ cells in experimental arthritis. J. Immunol. 178:7868-7878.

47. Anolik, J.H., et al. 2007. Delayed memory B cell recovery in peripheral blood and lymphoid tissue in systemic lupus erythematosus after B cell depletion therapy. Arthritis Rheum. 56:3044-3056.

48. Peng, J., et al. 2007. Converting antigen-specific diabetogenic CD4 and CD8 T cells to TGF-beta producing non-pathogenic regulatory cells following FoxP3 transduction. J. Autoimmun. 28:188-200. 